\title{
Analysis of Peculiarities of Using Digital Technologies in the University Professional Training Content
}

\author{
https://doi.org/10.3991/ijet.v16i20.24245 \\ Elvir Munirovich Akhmetshin $\left.{ }^{1}{ }^{凶}\right)$, Vladimir Lvovich Vasilev ${ }^{1}$, \\ Artemiy Vladimirovich Kozachek², Galina Vladimirovna Meshkova ${ }^{3}$, \\ Tatyana Nikolaevna Alexandrova ${ }^{4}$ \\ ${ }^{1}$ Kazan Federal University, Kazan, Russia \\ ${ }^{2}$ Tambov State Technical University, Tambov, Russia \\ ${ }^{3}$ Bauman Moscow State Technical University, Moscow, Russia \\ ${ }^{4}$ Saint-Petersburg State University of Industrial Technologies and Design, St. Petersburg, \\ Russia \\ elvir@mail.ru
}

\begin{abstract}
The relevance of the study is due to the increasing role of digital technologies in education. The abrupt shift of universities to distance learning during the COVID-19 pandemic has created new challenges. The purpose of this article is to analyze modern problems of traditional e-learning systems and identify the most effective digital technologies for improving the design system and implementing the content of professional educational programs at the university in the context of digitalization. Scientific articles in journals included in the Scopus database over the past five years, official websites of universities and their reports on the use of modern digital technologies were used as a statistical and empirical base for the study. Multiple comparative case studies and content analysis were applied. To solve the identified problems, such modern digital technologies and methods as cloud computing, adaptive design, big data, 3D printing, wearable technologies and gamification were proposed. The paper proposes an updated digital education system model at the university consisting of such elements as Instructors \& Students, Master Courses, Content Delivery, Courses Collaboration, Progress Tracking, Assignments, Practices and Exams. The conclusions and recommendations formulated in this study can be used by different educational systems and universities.
\end{abstract}

Keywords-digital education system, higher education, content of education, university professional training, distance education, new information and communication technologies

\section{Introduction}

Currently, the role of digital technologies is increasing in all spheres of economic and social activity, including education. The potential of digital technologies can improve the educational process. For universities, digital technologies are becoming a competitive advantage in modern conditions. Such a term as "competitive intelligence" 
with the help of a massive open online course is already becoming a key factor in university policies (Bleoju et al., 2019).

As noted in the literature, the main advantage of digital educational technologies is the ability to reduce the economic costs of organizing the educational process, its flexible change and implementation at a distance simultaneously for a significant number of students (Veselitsky et al., 2019; Evans-Amalu and Claravall, 2021).

Digital (distance) learning, in addition to the economic effect, can bring significant effects in pedagogical activity. Increasing the ability to provide educational material using various digital gadgets increases the cognitive activity of students (Tymoschuk et al., 2020). Digital technologies make it possible to customize the processes of monitoring student knowledge and feedback from the teacher in the most attractive form for all participants in the educational process (Wikström et al., 2019). In addition, mastering professional activities at the university using digital technologies allows obtaining digital competencies necessary in modern condition (Saliyeva et al., 2016).

On the other hand, total digitalization and a sharp increase in the role of digital technologies in the economy have led to the emergence of new threats and risks. There arise problems with the protection of personal data, commercial information and intellectual property (Cunha et al., 2020). An increase in the time of working at acomputer, a decrease in physical activity and an increase in psychological dependence on virtual reality have a negative effect on the health of students (Koryagina et al., 2019). There are also macroeconomic risks of digitalization: increasing digital inequality, unequal access to information and knowledge, social tensions and declining income equity (Mok et al., 2012). The open nature of the modern (global) digital education system poses threats to the national education system. The best talented students can study at any university in the world. This leads to a decrease in the national intellectual potential and the loss of the national identity of the educational system.

In addition, in the context of the COVID-19 pandemic and the sharp transition to a distance (remote) learning format, new problems have appeared in the operation of digital educational systems and technologies. Currently, the scientific literature lacks adequate research on the problems of digital transformation of universities. All of the above trends have determined the relevance of the present study.

Therefore, the purpose of this study is highlighting and analyzing the main problems of using digital technologies and determining the possibilities of using digitalization methods to improve the design system, implementation and management of the content of professional training of university students in the context of digitalization.

\section{Review of existing electronic technologies for the design and implementation of training content, problem statement}

One of the teaching methods, in which the learner concentrates on activities and learning based on his abilities, is the traditional e-learning method, which has a long history of using electronic technology. This type of education at one time in the 1980s and early 2000 s revolutionized the search for information in the modern technological world and was taken into account, despite such problems as the growing demand for 
higher education and insufficient funding, lack of full-time teachers and the need to remove geographic restrictions (Kalimullina et al., 2021).

Traditional electronic technologies for the design of content and implementation of education in the context of digitalization include the following:

1. Classroom method - associated with the physical presence of students and teachers in the same classroom. This method has limitations in the number of trainees, in time, in economic costs. This method corresponds to the traditional university model.

2. E-learning - this method has become possible with the advent of computer and multimedia technology. E-learning has become a tool for improving the qualifications of personnel, opening up opportunities for modeling any processes in nature and human life. Electronic technologies have made it possible to replicate information and knowledge in the most convenient form and with high economic efficiency (Prihartini et al., 2016; Musumba et al., 2019).

3. Network Learning - this method is associated with the emergence of the Internet and other networks of various sizes. Local networks are actively used within the educational organization, allowing for automating both educational and administrative activities at the university. Thanks to network technologies, it has become possible to expand the scope of classroom teaching and customize feedback between teacher and student (Ivanov, 2019; Johnson, 2001).

4. Distance learning - this method has made it possible to expand the educational opportunities of universities for a significant number of students. Moreover, thanks to distance learning, universities are expanding around the world. Education has become a global thing. Being anywhere in the world, you can remotely acquire education at any university. The peculiarity of distance education is that it has turned into a separate institute with its own requirements, norms and principles, rules of interaction between teachers and students (Diwakar et al., 2015; Diwakar et al., 2019).

5. Online learning - this learning method is characterized by time independence and the ability to connect to the educational program at any time (Nakajima et al., 2015; Ono et al., 2017).

6. Learning assisted with intelligent support agents - this method is based on artificial intelligence technology. An intelligent agent is a system that can learn by itself and offer the best training option for students. A feature of this method is the close relationship of an intelligent agent, teacher and student (Scott et al., 2016; Xu et al., 2014; Herrero et al., 2005).

7. Adaptive Learning - this teaching method is based on the study of the national characteristics of education, the specifics of the economy and the requirements for a university graduate (Trikha et al., 2016; Vanitha et al., 2019).

8. Knowledge-based learning - this teaching method uses an analysis of the knowledge acquired by students during the year. The study of a student's digital footprint makes it possible to develop recommendations for adjusting his individual educational trajectory. At the same time, training can take place in a group mode as part of a professional higher education program (George et al., 2019; Sangodiah et al., 2012). 
9. Decision support system training - it is a teaching method that helps the teacher make decisions about the choice of educational content. The system helps to select the types and forms of educational material that is adequate to the individual and social characteristics of students (Jeong et al., 2012; Xie et al., 2019).

However, the rapid changes in information and communication technologies, and especially in the information society, brought about by the Internet-based e-learning environment, make traditional e-learning ineffective (Bartschat et al., 2019).

The current situation with the COVID-19 pandemic, resulting in the whole world being in a jerk immersed in a digital learning environment, often against will, has shown that traditional e-learning methods have generally failed to cope with the surging wave of professional and educational tasks. This was especially evident in the conditions of the massive transition of the world's population to e-learning. We believe that this is due to a number of contradictions emerging between the requirements of society for digital education systems and the real possibilities of traditional e-learning technologies.

This throws into sharp relief the question of a systematic approach to the design and implementation of the content of vocational training in universities in the context of digitalization.

Due to the widespread demand for digital learning on the one hand, and the inability of the existing system to respond to it, as well as the many possibilities of modern digital learning methods on the other hand, the organization and development of such learning systems should become a necessity.

Unfortunately, at the present time we have not yet managed to find scientific papers considering this issue with due completeness and consistency.

\section{Methodology}

The study used materials available in the scientific literature on existing and new information and communication technologies, which in the context of digitalization of higher education, in our opinion, can be used for the design and implementation of the content of professional training in universities.

The logic of the study is as follows: firstly, it is necessary to analyze and assess the possibilities and directions of application of information and communication technologies for the purpose of designing and implementing the content of professional training in universities in the context of digitalization, and secondly, it is necessary to make a synthesis within which it is possible to develop a system for designing and implementing the content of vocational training in universities in the context of digitalization.

To identify the existing problems of traditional e-learning and search for promising new digital technologies that allow solving these problems within the framework of the new digital education system, the method of multiple thematic comparative studies was applied.

The study was carried out on three groups of information sources: 
1. Publications of articles from the Scopus database for 2015-2020. The percentage of mentioning the object of research was calculated.

2. Content analysis on the Internet. The percentage of the research object's presence on the Internet was calculated.

3. Official websites of universities. The percentage of the use by experts - university teachers of the object of study was calculated.

Based on the three indicators, an integral indicator was calculated as a simple arithmetic mean of the three indicators.

To collect materials and process statistical information, a special analytical data matrix was used, presented in Table 1.

Table 1. Matrix for the analysis of peculiarities of using digital technologies in the content of university professional training

\begin{tabular}{|c|c|c|c|c|}
\hline Analysis objects & $\begin{array}{c}\text { Percentage of mentioning } \\
\text { in scientific articles } \\
\text { (1) }\end{array}$ & $\begin{array}{l}\text { Percentage of pres- } \\
\text { ence on Internet } \\
\text { (2) }\end{array}$ & $\begin{array}{c}\text { Percentage of } \\
\text { use by experts } \\
\text { (3) }\end{array}$ & $\begin{array}{l}\text { Integral } \\
\text { indicator } \\
(1+2+3) / 3\end{array}$ \\
\hline \multicolumn{5}{|c|}{ Identified problems with traditional e-learning } \\
\hline \multicolumn{5}{|l|}{ Problem 1} \\
\hline \multicolumn{5}{|l|}{ Problem 2} \\
\hline \multicolumn{5}{|l|}{ Problem N } \\
\hline Total & $100 \%$ & $100 \%$ & $100 \%$ & \\
\hline \multicolumn{5}{|c|}{ New promising digital technologies in education } \\
\hline \multicolumn{5}{|l|}{ Technology 1} \\
\hline \multicolumn{5}{|l|}{ Technology 2} \\
\hline \multicolumn{5}{|l|}{ Technology N } \\
\hline Total & $100 \%$ & $100 \%$ & $100 \%$ & \\
\hline \multicolumn{5}{|c|}{ Essential elements of a new digital education system at the university } \\
\hline \multicolumn{5}{|l|}{ Element 1} \\
\hline \multicolumn{5}{|l|}{ Element 2} \\
\hline \multicolumn{5}{|l|}{ Element $\mathrm{N}$} \\
\hline Total & $100 \%$ & $100 \%$ & $100 \%$ & \\
\hline
\end{tabular}

Source: author's research methodology.

Eventually, the obtained results, according to the collected data, made it possible to determine the priority areas for solving the problems of traditional e-education at the university and to select the most promising digital technologies for improving the education system of higher education.

\section{$4 \quad$ Results}

We present the main results of the study. The research object is the traditional system of e-learning at the university. The research subject is the problems of this system and solutions using new digital technologies. It is necessary to propose the composition and structure of the updated digital education system at the university. 
Let us consider the first direction of our research - the problems of the traditional elearning system (Figure 1). As a result, the analysis of the collected and processed statistical data has made it possible to draw the following conclusions:

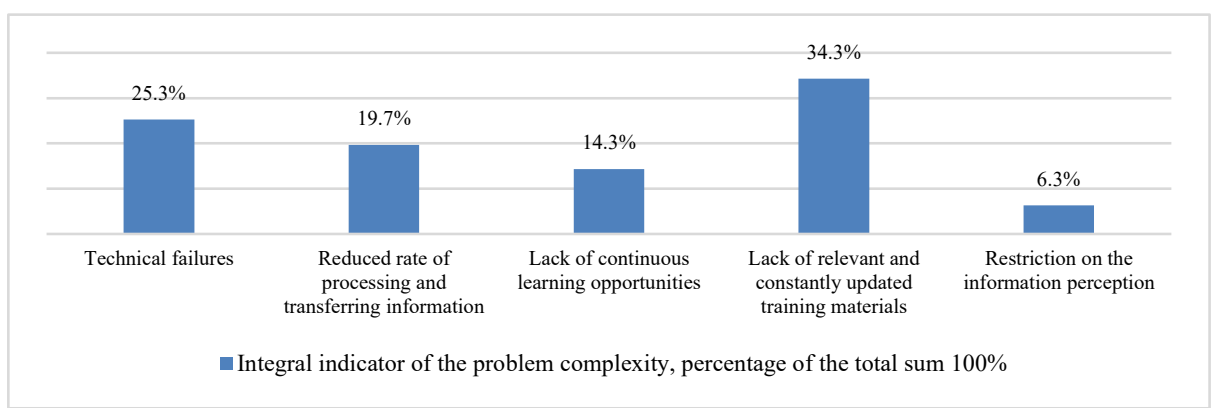

Fig. 1. Problems with traditional e-learning system

- Technical failures with the simultaneous work of millions of people. The integral indicator of the complexity of the problem was $25.3 \%$. Traditional information educational systems were not designed for and did not cope with large data streams, there were delays, freezes and collapse of Internet portals, educational information systems as a result of attempts to connect millions of people to them at once within a short period of time.

- Reduced rate of processing and transferring information. The integral indicator of the complexity of the problem was $19.7 \%$. Traditional electronic learning technologies did not imply the need to store huge arrays of educational information for billions of people, as a result of which problems arose with the extraction of the necessary information, its fast transmission and processing;

- Lack of opportunities for continuous learning (geographic, time and functional lifelong learning provision). The integral indicator of the complexity of the problem was $14.3 \%$. Traditional e-learning technologies did not use the technical possibilities of modern gadgets, such as connecting to portable mobile multimedia devices, 3D printing, game consoles, etc., as a result of which many people, especially those on business trips, travels having no stationary computers and laptops were deprived of e-learning opportunities;

- Lack of relevant and constantly updated training materials. The integral indicator of the complexity of the problem was $34.3 \%$. The content of academic disciplines, courses, models, areas of training in general in the context of an abrupt massive transition to traditional e-learning turned out to be outdated, based on old information components previously posted on the Internet and information systems on the portals of universities, and educational information systems turned out to be not ready to adapt the content of vocational training to drastic changes;

- Restriction on the information perception. The integral indicator of the complexity of the problem was $6.3 \%$. Traditional e-learning information systems did not always 
provide the necessary visualization, especially 3D-dimensional, of educational content, which reduced the possibilities for the information perception by students and its effective presentation by teachers.

The above shortcomings of traditional e-learning technologies resulted in the actual collapse of the mass digital learning system at the beginning of the COVID-19 pandemic and its failure to provide the necessary efficiency in the design of the content and implementation of training or the required level of formation of professional competencies of students.

Let us consider the second direction of our research - new digital technologies that can be applied at the university to improve the system of design and implementation of the content of professional higher education programs.

Today, a variety of web applications in the field of education have been developed and used in the form of modern learning tools in various educational organizations and educational online sites. Online learning is gradually becoming a trend in education.

To avoid the problems identified above, digital learning today must take advantage of modern technologies such as the Internet, databases and knowledge management, and deliver educational content through e-services.

The development of new concepts such as gamification and new technologies such as cloud computing, the Internet of Things, big data, responsive e-learning design, as well as portable technologies, 3D printing and mobile technologies are playing an unprecedented role in e-learning. Therefore, it is precisely these technologies that we propose to use in the design, implementation and management of professional training of students in universities in the context of digitalization.

The research carried out according to the author's methodology revealed the following rating of new digital technologies intended for use in the system of design, implementation and management of the content of professional training of students at the university (See Figure 2):

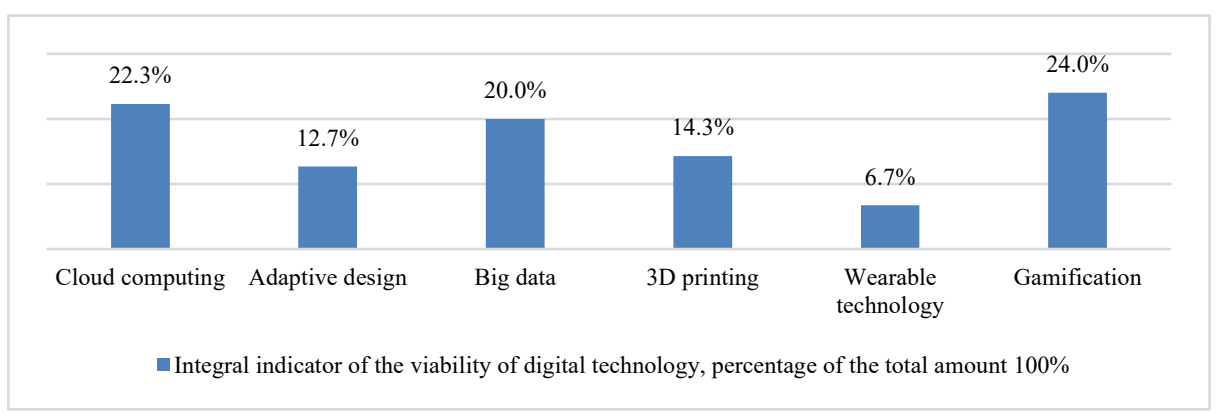

Fig. 2. New digital technologies promising for the university

1. Cloud computing is a technology based on the accumulation of data and knowledge in a separate digital storage. The integral indicator of the viability of this technology for the university was $22.3 \%$. Cloud technologies and cloud classrooms at universities can improve the educational process, increase its resource component by storing, 
processing and transferring a significant amount of data and knowledge. (Alam et al., 2017).

Cloud technologies allow solving pedagogical problems of any level, both for a group and for an individual format. Cloud technologies work through virtual reality and enable the enhancement of traditional e-learning systems. The problem of limited storage of information is solved with the help of cloud technologies. For example, Massive Open Online Course (MOOC) is an accessible, cloud-based and Internet-based learning platform (Korableva et al., 2019).

2. Adaptive (responsive) eLearning design is a technology allowing one to tailor educational content for students. The process of assessing the perception of incoming information by students becomes the main one. Based on the identified features of motivation and mastering of knowledge by students, adequate types and forms of the educational process are selected. More traditional names are workplace ergonomics, teacher workstation, etc. The integral indicator of the viability of this technology for the university was $12.7 \%$.

3. Big data is a technology that tracks large amounts of heterogeneous, unrelated information and allows it to be used to solve specific problems. The integral indicator of the viability of this technology for the university was $20.0 \%$. In digital learning systems, big data will make it possible to form a student's digital footprint, compile his digital profile and develop an individual learning path within a professional higher education program (Roosta et al., 2016).

4. $3 \mathrm{D}$ printing is a technology that allows one to create and study three-dimensional objects. The integral indicator of the viability of this technology for the university was $14.3 \%$. This technology has a powerful practice-oriented potential, allowing for creating educational models of building struc-tures, industrial designs, various details of technology, engineering systems for environmental protection. This technology is not used enough in education at present and is going to be in a more active demand in the near future (Rozi et al., 2019).

5. Wearable technologies are technologies that allow for continuous education of a student, regardless of his geographical location. There are special devices for the student to be constantly present in the educational process: smart glasses, augmented reality headsets, hybrid virtual reality headsets, smart phones. The integral indicator of the prospects of this technology for the university was $6.7 \%$.

6. Gamification is a technology that uses a game approach to teach students complex professional skills and abilities. It has been proven that through the game, students more effectively master the necessary professional knowledge, skills and abilities. The formation of professional competencies through the game format is also faster. The game increases the cognitive activity of students. Digital technologies make the game even brighter, more interesting and more useful for students and for higher education. The integral indicator of the viability of this technology for the university was $24 \%$. In gamification, natural incentives are used to drive the audience (Hassan et al., 2019). 
Let us consider the third direction of our research - the possible composition and structure of a digital system for the design, implementation and management of the content of professional training of students (See Figure 3).

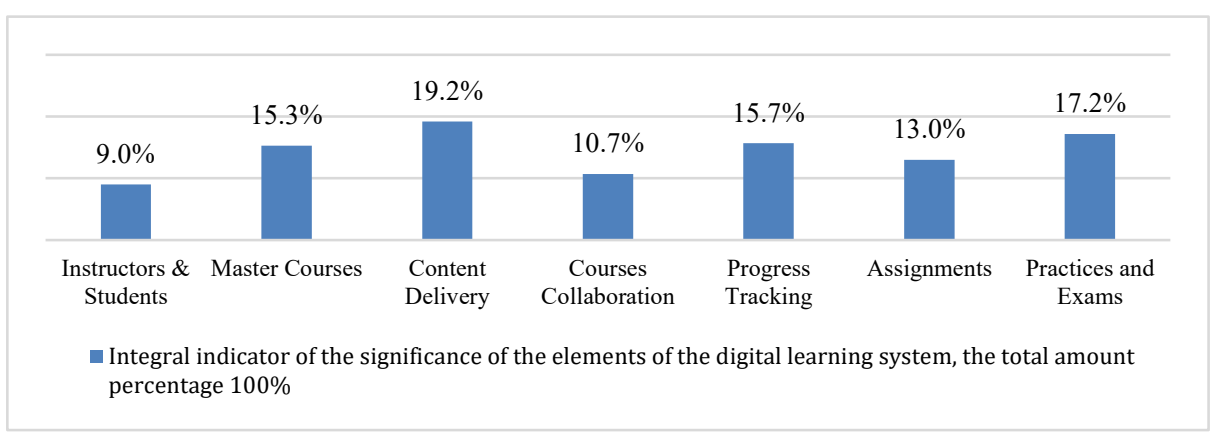

Fig. 3. Significance of a digital education system element at a university

We believe that the system for designing, implementing and managing the content of vocational training in universities in the context of digitalization should, in addition to the design process itself, also allow organizing the management of such a process. Therefore, this system should include such elements as:

- persons who make decisions about individual aspects or the entire technology of designing and implementing the content of vocational training in universities and focusing in this on the use of modern information and telecommunication technologies, and students who are the main consumers of the content of vocational training (Instructors \& Students in Figure 1). The integral indicator of the significance of this element was $9.0 \%$;

- designing the content of training courses, disciplines (Master Courses in Figure 1). The integral indicator of the significance of this element was $15.3 \%$;

- technologies for delivering the content of training courses, disciplines to the student, for example, by using various modern teaching methods in the context of digitalization, including e-learning and distance learning technologies (Content Delivery in Figure 1). The integral indicator of the significance of this element was $19.2 \%$;

- ensuring the relationship between training courses, disciplines, the mutual sequence of their study by students in order to qualitatively form the necessary professional competencies (Courses Collaboration in Figure 1). The integral indicator of the significance of this element was $10.7 \%$;

- the first control subsystem, which serves to track the progress and effectiveness of the design and implementation of the content of vocational training in universities in the context of digitalization, with the tracking being carried out through an assessment of the content of vocational training in terms of the adequacy of didactic units to the requirements of professional activity, the relevance of the pedagogical methods used, the modernity of the implemented information and telecommunication technologies (Progress Tracking in Figure 1). The integral indicator of the significance of this element was $15.7 \%$; 
- a subsystem for setting and correcting tasks posed at the beginning of the process of design and implementation of the vocational training content in universities in the context of digitalization and adjusted during the process in cases of its deviation from the required trajectory (Assignments in Figure 1). The integral indicator of the significance of this element was $13.0 \%$;

- the second subsystem of control, or the subsystem of certification (receiving reports on practices, exams, etc.), which serves as the second subsystem for tracking the progress and effectiveness of the design and implementation of the content of professional training in universities in the context of digitalization, when tracking is organized through assessing the level of formation of students' competencies when studying courses, disciplines, modules, programs in general (Practices and Exams in Figure 1). The integral indicator of the significance of this element was $17.2 \%$.

As a result, the model of the system for the design, implementation and management of the content of vocational training in universities in the context of digitalization will take the form shown in Figure 4.

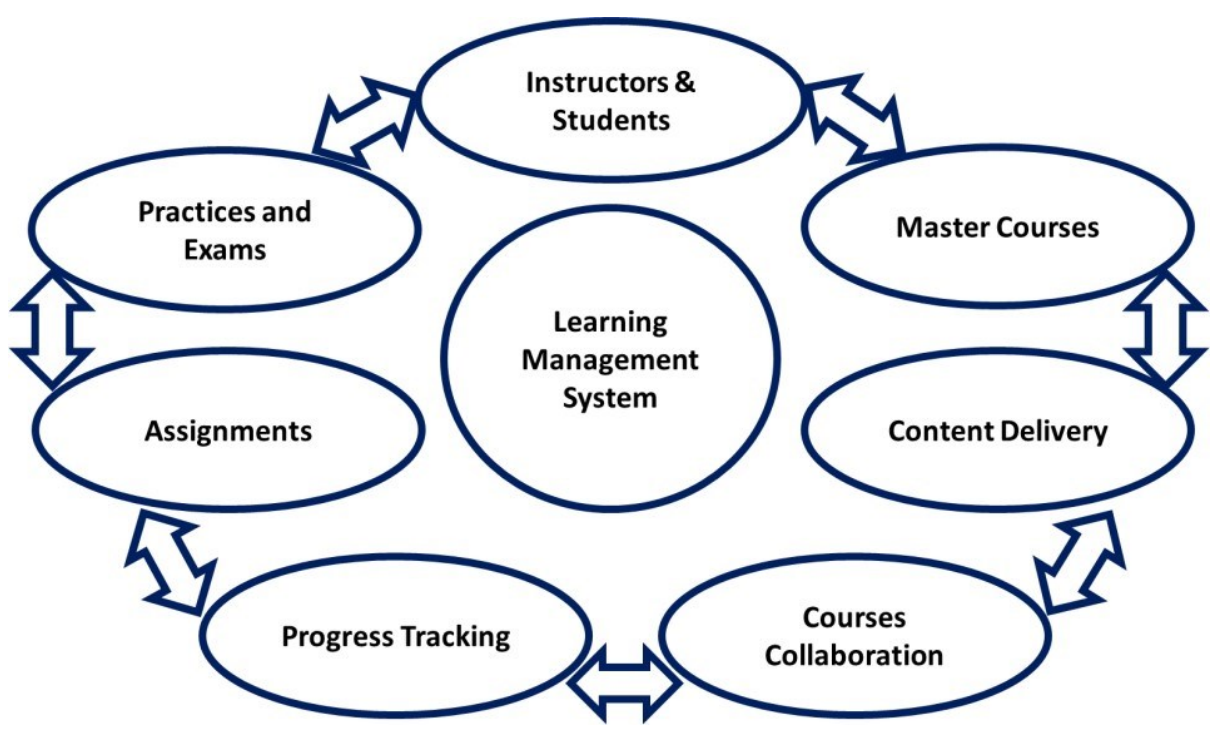

Fig. 4. Model of a system for the design, implementation and management of the content of vocational training in universities in the context of digitalization

In our understanding, the content of vocational training is a set of didactic units (topics, disciplines, modules) reflecting systematized information on various aspects of the professional activity of a university graduate, arranged in a certain order of study and interrelated by various types of connections (Kozachek, 2015).

We suggest the idea of the process of designing the content of vocational training at a university in the context of digitalization to be the activity of specific individuals (teachers, heads of departments, etc.), or automated information systems of pedagogical 
design, or their interaction aimed at determining the requirements for professional activity of a graduate, identifying and assessing the importance of various aspects of such activities, grouping them according to connecting characteristics and processing the collected information in groups into specific didactic units with the definition of the sequences and time of their study, didactic relations between them.

By the process of implementing the content of vocational training of students at a university in the context of digitalization, we mean the activities of teachers, students and automated systems coordinated by them in planning, implementing and quality control of the application of the previously developed content of vocational training directly for teaching students in a specific area, specialty using learning digitalization technologies.

Both processes should be united by a management system for the design and implementation of vocational training content in universities in the context of digitalization. The proposed model using the above new e-learning technologies is to ensure the required quality and efficiency of the design, implementation and management of the content of professional training of students in universities.

\section{Discussion}

Modern information and telecommunication technologies, in our opinion, can play a significant role in increasing the efficiency of design, implementation and management systems of the content of professional training of university students in the context of digitalization.

Above, we have developed an innovative system for the design, implementation and management of the content of professional training of students in universities and identified the main modern digital technologies that can be used for the effective implementation of such a system.

The analysis of scientific literature and opinions of scientists and experts on this topic has shown the results presented below.

Scientists note that new digital technologies make it possible to increase the level of collaboration between teachers and students. Such a necessary factor as digital trust can only be improved in the conditions of feedback between teacher and student and constantly updated educational content (Frolova et al., 2020).

Other scholars are focusing on related learning. In this case, students can work together on any educational and scientific projects, easily communicating with each other and their teachers by e-mail and video chat, as well as gaining access to the Scientific Learning Network and joint solutions. Collaborative creativity enhances digital education resources (Manrique-Losada et al., 2020).

A digital learning system is capable of accumulating information and knowledge for use in the future. This is also noted by scientists and experts. Teachers and students are the two main elements of the formation of e-classes within the proposed system. But many lessons are usually recorded and can be comprehensively used in the future. This means that eclasses can be reused. Sharing knowledge and experience through digital 
technology plays a key role in improving the quality of life in general (Razumovsky et al., 2020).

Another important advantage of digital educational technologies, according to the general opinion of scientists and experts, is the possibility of learning without territorial boundaries (Borderless). E-learning in the proposed system crosses the boundaries of the classroom walls, and information and people are available everywhere. This type of education is very beneficial for students living in remote areas and for social justice. The challenge for the near future is to overcome the digital divide and ensure equal access for all to relevant databases and knowledge (Gremigni et al., 2018).

As scientists and experts note, digital education is a part of the digital economy, and it, in turn, allows for the rapid social and economic development of the territory. Digital learning takes place in a community, be it a learning community designated by a specific educational institution, university, or in a real physical community such as a city. E-learning can connect communities by increasing accessibility and communication (Zabaznova et al., 2020).

Plus, digital learning can be done through research. Many online studies are a kind of pre-training. Similar to computer games, they can be a lot of fun, opening the way to play. Learning lessons can be fun too. A more formal type is the discovery and study of problems that are commonly used in specialized training. In this approach, problem situations are presented to students who are encouraged to work on identifying and producing solutions and strategies. Gamification is an effective tool for the future of digital learning (Barabanova et al., 2019).

Digital educational technologies (massive open online courses) take the knowledge exchange process to a new level. Knowledge sharing is the foundation of education, but before the creation of computer networks, knowledge sharing was limited to books and magazines. Placing information on the Internet or any other electronic equipment makes it more accessible to other people (Al-Rahmi et al., 2019).

Digital educational technologies allow the use of many ways to deliver knowledge to the consumer. The use of such methods as image, color, movement and touch in the process of e-learning, especially through $3 \mathrm{D}$ printing and gamification technologies, is quite effective for the formation of professional competencies (Wahab et al., 2019).

One of the important factors in practicing the proposed system of design, implementation and management of the content of professional training of university students in the context of digitalization is the possibility of continuous interaction between all participants in educational activities (Sorokova, 2020).

The audience can view materials and interact with their learning units at any time. One can say that e-learning is potentially available anytime, anywhere. Recent developments in information and communication technology and the penetration of telecommunication tools into homes and offices have brought about changes in teaching tools and devices, and now the audience can interact with education management systems, with a computer terminal or even a mobile device anywhere, and they can at any time find out the content provided (Vougas et al., 2019).

Another factor is that this flexible and interactive learning style provides informative learning materials with a variety of content to suit their needs. This is important in the context of constant changes in production, environmental and other technologies, 
which also contributes to the requirements for changing educational information in order to ensure the adequacy of the content of professional training of students at the university to the content of the professional activities of workers at different enterprises. It is digital technologies in education that make it possible to timely and efficiently ensure such adequacy.

It also creates great flexibility in teaching methodology, learning management system, simultaneous and asynchronous interaction between teachers and students, organization and structure of courses, educational projects and, finally, effective and reliable assessment of students, which allows one to reconfigure the educational process from focusing on teaching to focusing on training (Landeros et al., 2016; Nguyen et al., 2019).

Also, the proposed system for the design, implementation and management of the content of professional training of university students in the context of digitalization will allow removing the previously identified contradictions between the requirements of society for digital education systems and the real possibilities of traditional e-learning technologies, including the following:

- providing the ability to work with large data streams with the ability to connect large numbers of students;

- providing the ability to store huge arrays of educational information, transfer and process it;

- making use of the technical capabilities of modern gadgets, such as connection to wearable mobile multimedia devices, 3D printing, game consoles, etc.;

- ensuring the relevance and adequacy of the content of academic disciplines, courses, models, areas of training in general to changes in the content and requirements for the professional activities of graduates;

- providing the necessary visualization of educational content, which will increase the efficiency of the perception of information by students and its effective presentation by teachers.

Thus, the results obtained in our study are consistent with the results of other scientists and experts presented in the scientific literature.

\section{$6 \quad$ Key insights}

Digital technologies are widely used in our life. Digital technologies have become widespread in education. It has allowed for a distance learning format without leaving the place of residence and work. This has made it possible to meet the growing demand for education. The growth of information, knowledge and new technologies has led to the need for continuous learning. Today, all traditional educational systems of universities are forced to transform into digital ones. This allows us to meet the growing mass demand for knowledge. On the other hand, this has resulted in a loss in the quality of teaching, a decrease in cognitive motivation and an increase in the gap between fundamental and practical knowledge. Amid the COVID-19 pandemic, new problems have emerged. 
In the present paper, the following new scientific results were obtained:

1. An analysis of the problems of traditional e-learning was performed and an assessment of their complexity was carried out (the total complexity of all problems was $100 \%)$. The most difficult problem was the lack of relevant, constantly updated training materials $(34.3 \%)$. The problem of limiting the perception of information has the least complexity $(6.3 \%)$. Other problems - technical failures $(25.3 \%)$, a decrease in the speed of transmission and information processing (19.7\%), lack of opportunities for continuous learning (14.3\%) also require an integrated approach to their solution.

2. The analysis of new digital technologies was made that could solve the problems arising in education at the present time. An assessment of their prospects was carried out using the author's methodology (the overall viability of all new digital technologies was $100 \%$ ). It is proposed to use such methods and technologies as gamification $(24 \%)$, cloud computing $(22.3 \%)$, working with big data $(20 \%)$, 3D printing $(14.3 \%)$, adaptive design $(12.7 \%)$ and wearable technologies $(6.7 \%)$. Such a rating of methods and technologies will help develop the most effective university digitalization policy. In conditions of limited resources, more promising methods and technologies should be applied first. They will have the greatest effect in solving the identified problems of the present time.

3. The analysis of the significance of the elements of the digital education system at the university was carried out. The overall significance of all elements is $100 \%$. An assessment was made of such necessary elements as Instructors \& Students $(9.0 \%)$, Master Courses (15.3\%), Content Delivery (19.2\%), Courses Collaboration (10.7\%), Progress Tracking (15.7\%), Assignments (13.0\%), Practices and Exams (17.2\%). It should be noted that the elements responsible for current and final control, for feedback from students and for educational content, which should be relevant and consistent with other elements of the digital learning system at the university, have the greatest weight.

Thus, the methodology developed by the authors for assessing the problems of the traditional e-learning system, new digital educational technologies and the necessary elements of the digital education system allows structuring and optimizing the university's digital transformation policy.

\section{Conclusion}

The emergence of digital educational technologies is due to two reasons: scientific and technological progress and the need for rational use of limited economic resources. Modern digital educational technologies make it possible to improve the quality of the educational process while minimizing the cost of operating the university.

With all the known advantages of digital educational systems, they need to be improved, since in the conditions of the massive transition to distance learning during the COVID-19 pandemic, new problems have appeared. The paper presents an assessment of the level of complexity of these problems. It proposes new digital educational technologies that can solve the arising problems. 
The proposed new digital educational technologies should be practiced within the framework of the design, implementation and management of the content of professional training of students in universities, a model of which is proposed in this paper.

As a result of the application of the proposed measures, the effectiveness of the digital education system at the university can be significantly increased.

\section{Acknowledgement}

The reported study was funded by RFBR, project number 19-29-07037.

\section{$9 \quad$ References}

[1] Alam, A., Ullah, S., \& Ali, N. (2017). The effect of learning-based adaptivity on stu-dents' performance in 3D-virtual learning environments. IEEE Access., 6, 3400-3407. https://doi. org/10.1109/access.2017.2783951

[2] Al-Rahmi, W., Aldraiweesh, A., Yahaya, N., Bin Kamin, Y., \& Zeki, A. M. (2019). Massive open online courses (MOOCs): Data on higher education. Data in Brief, 22, 118-125. https://doi.org/10.1016/i.dib.2018.11.139

[3] Barabanova, S. V., Kaybiyaynen, A. A., \& Kraysman, N. V. (2019). Digitalization of education in the global context. Vysshee Obrazovanie v Rossii, 28(1), 94-103. https://doi.org/ 10.31992/0869-3617-2019-28-1-94-103

[4] Bartschat, A., Reischl, M., \& Mikut, R. (2019). Data mining tools. Wiley. Interdiscip. Rev. Data. Min. Knowl. Discov., 9(4), e1309. https://doi.org/10.1002/widm.1309

[5] Bleoju, G., Capatina, A., Vairinhos, V., Nistor, R., \& Lesca, N. (2019). Empirical evidence from a connectivist competitive intelligence massive open online course (CI cMOOC) proof of concept. Journal of Intelligence Studies in Busi-ness, 9(3), 7-23. https://doi.org/10.37380/ jisib.v9i3.512

[6] Cunha, M. N., Chuchu, T., \& Maziriri, E. T. (2020). Threats, challenges, and oppor-tunities for open universities and massive online open courses in the digital revolution. International Journal of Emerging Technologies in Learning, 15 (12), 191-204. https://doi.org/10.3991 /ijet.v15i12.13435

[7] Diwakar, S., Kumar, D., Radhamani, R. Nizar, N., Nair, B., Sasidharakurup, H., \& Achuthan, K. (2015). Role of ICT-enabled virtual laboratories in biotechnolo-gy education: Case studies on blended and remote learning. International Conference on Interactive Collaborative Learning (ICL), 915-921. IEEE. https://doi.org/10.1109/ic1.2015.7318149

[8] Diwakar, S., Radhamani, R., Sujatha, G., Sasidharakurup, H., Shekhar, A., Achuthan, K., Nair, B. (2019). Usage, and diffusion of biotechnology virtual labs for en-hancing university education in India's urban and rural areas. In Virtual Reality in Education: Breakthroughs in Research and Practice, 433-453. IGI Global. https://doi.org/10.4018/978-1-5225-81796.ch022

[9] Evans-Amalu, K., \& Claravall, E. (2021). Inclusive Online Teaching and Digital Learning: Lessons Learned in the Time of Pandemic and Beyond. Journal Of Curriculum Studies Research, 3(1), i-iii. https://doi.org/10.46303/jcsr.2021.4

[10] Frolova, E. V., Rogach, O. V., \& Ryabova, T. M. (2020). Digitalization of education in modern scientific discourse: New trends and risks analysis. European Jour-nal of Contemporary Education, 9(2), 331-336. 
[11] George, G., \& Lal, A. M. (2019). Review of ontology-based recommender systems in elearning. Comput. Educ., 142, 103642. https://doi.org/10.1016/j.compedu.2019.103642

[12] Gremigni, E. (2018). Overcoming new forms of digital divide: Some remarks on the need for media education. Italian Sociological Review, 8(1), 81-102. http://dx.doi.org/10. 13136/isr.v8i1.221

[13] Hassan, M. A., Habiba, U., Majeed, F., \& Shoaib, M. (2019). Adaptive gamification in elearning based on students' learning styles. Interact. Learn. Environ., 1-21. https://doi.org/ $\underline{10.1080 / 10494820.2019 .1588745}$

[14] Herrero, P., Greenhalgh, C., \& De Antonio, A., Being on guard: intelligent virtual agents reporting information from collaborative virtual environments. J. Pres-ence., 14(4), 2005,

[15] 423-433. https://doi.org/10.1162/105474605774785280

[16] Ivanov, I. D. (2019). Use of Interactive Student Response Software in an Introductory International Relations Course. J. Political Sci. Educ., 1-18.

[17] Jeong, H. Y., Choi, C. R., \& Song, Y. J. (2012). Personalized Learning Course Planner with E-learning DSS using a user profile. Expert Syst. Appl., 39(3), 2567-2577. https://doi.org/

[18] 10.1016/j.eswa.2011.08.109

[19] Johnson, S. M. (2001). Teaching Introductory International Relations in an Entirely Webbased Environment: Comparing Student Performance across and Within Groups. Int. J. Distance. Educ. Technol., 15(10), 10.

[20] Kalimullina O. Tarman B., \& Stepanova I. (2021). Education in the Context of Digitalization and Culture: Evolution of the Teacher's Role, Pre-pandemic Overview. Journal of Ethnic and Cultural Studies, Vol. 8, No. 1, 226-238 https://doi.org/10.29333/ejecs/629

[21] Korableva, O., Durand, T., Kalimullina, O., \& Stepanova, I. (2019). Usability testing of MOOC: Identifying user interface problems. Paper presented at the ICEIS 2019 - Proceedings of the 21st International Conference on Enterprise Information Systems, 2, 468-475. https://doi.org/10.5220/0007800004680475

[22] Koryagina, E.D. (2019). Digital Avatar of Education. Theoretical Economics, 2(50). Retrieved from: https://cyberleninka.ru/article/n/tsifrovoy-avatar-obrazovaniya

[23] Kozachek, A.V. (2015). The concept of the university professional training content for an environmental engineer. Alma mater (Bulletin of the higher school), 8, 52-57.

[24] Landeros, J. R., \& Fuentes, M. D. L. M. (2016). Development of a Framework for the Use of a Tool for Machine Learning and Data Mining. Res. Comput. Sci., 122, 127-139.

[25] Manrique-Losada, B., Zapata Cárdenas, M. I., \& Arango Vásquez, S. I. (2020). Virtu-al environment to co-create digital educational resources in higher education. [Entorno virtual para cocrear recursos educativos digitales en la educación su-perior] Campus Virtuales, 9(1), 101-112

[26] Mok, K. H., \& Leung, D. (2012). Digitalisation, educational and social development in greater china. Globalisation, Societies and Education, 10(3), 271-294. https://doi.org/10. $\underline{1080 / 14767724.2012 .710118}$

[27] Musumba, G., \& Wario, R. (2019). Towards a Personalized Adaptive Remedial e-Learning Model. IST-Africa Week Conference (IST-Africa), 1-11. IEEE. https://doi.org/10.23919/ istafrica.2019.8764848

[28] Nakajima, A., \& Ono, Y. (2015). The Prospect of Open Online e-Learning System Based on the Free Culture Movement-Development of You Tutors as an Auto-Assignment Generator by Utilizing Creative Commons Contents Online. IIAI 4th International Congress on Advanced Applied Informatics, 397-402. IEEE. https://doi.org/10.1109/iiai-aai.2015.277

[29] Nguyen, G., Dlugolinsky, S., Bobák, M., Tran, V., García, Á. L., Heredia, I., \& Hluchý, L. 
Paper-Analysis of Peculiarities of Using Digital Technologies in the University Professional Training...

[30] (2019). Machine Learning and Deep Learning frameworks and libraries for large-scale data mining: a survey. Artif. Intell. Rev., 52(1), 77-124. https://doi.org/10.1007/s10462$\underline{01809679-Z}$

[31] Ono, Y., Nakajima, A., \& Ishihara, M. (2017). Motivational effects of a game-based automatic quiz generator using online educational resources for Japanese EFL learners. in Society for Information Technology \& Teacher Education. International Conference, 258-265. AACE.

[32] Prihartini, N., Soemitro, H. L., \& Hendradjaya, B. (2016). Identifying aspects of web elearning in LMS-based for requirement engineering process modeling. Inter-national Conference on Data and Software Engineering (ICoDSE), 1-6. IEEE. https://doi.org/ 10.1109/icodse. 2016.7936134

[33] Razumovsky, V. M., Sultanova, A. V., Chechina, O. S., \& Nikonorova, S. A. (2020). The impact of the digital economy on the quality of life. https://doi.org/10.1007/978-303029586-8 48

[34] Roosta, F., Taghiyareh, F., \& Mosharraf, M. (2016). Personalization of gamification-elements in an e-learning environment based on learners' motivation. 8th International Symposium on Telecommunications (IST), 637-642. IEEE. https://doi.org/10.1109/istel. $\underline{2016.7881899}$

[35] Rozi, F., Rosmansyah, Y., \& Dabarsyah, B. (2019). Systematic Literature Review on Adaptive Gamification: Components, Methods, and Frameworks. International Conference on Electrical Engineering and Informatics (ICEEI), 187-190. IEEE. https://doi.org/10.1109/ iceei47359.2019.8988857

[36] Saliyeva, A. Z., Zhumabekova, F. N., Kashkynbay, B. B., Saurbekova, G., Tauasarova, D., Toktarbaev, D., \& Sakenov, J. (2016). On the students' ability to use digital educational resources. International Journal of Environmental and Science Education, 11(11), 46694679

[37] Sangodiah, A., \& Heng, L. E. (2012). Integration of data quality component in an ontologybased knowledge management approach for an e-learning system. International Conference on Computer \& Information Science (ICCIS), 1, 105-108. IEEE. https://doi.org/10.1109/ iccisci.2012.6297221

[38] Scott, E., Soria, A., \& Campo, M. (2016). Adaptive 3D virtual learning environments - A review of the literature. IEEE Trans. Learn. Technol., 10(3), 262-276. https://doi.org/10. $\underline{1109 / \text { tlt.2016.2609910 }}$

[39] Sorokova, M. G. (2020). E-course as blended learning digital educational resource in university. [Электронный курс как цифровой образовательный ресурс смешанного обучения в условиях высшего образования] Psychological Science and Education, 25(1), 36-50.

[40] https://doi.org/10.17759/pse.2020250104

[41] Trikha, N., \& Godbole, A. (2016). Adaptive e-learning system using a hybrid ap-proach. International Conference on Inventive Computation Technologies (ICICT), 2, 1-4. IEEE. https://doi.org/10.1109/inventive.2016.7824844

[42] Tymoschuk, N. A., Ryabinova, E. N., Sapova, O. A., \& Oddo, V. (2020). Matrix model of cognitive activity as one of the meta basis of digital education. Ad-vances in Intelligent Systems and Computing, 908, 481-493. https://doi.org/10.1007/978-3-030-11367-4_48

[43] Vanitha, V., Krishnan, P., \& ELakkiya, R. (2019). Collaborative optimization algo-rithm for learning path construction in E-learning. Comput. Electr. Eng., 77, 325-338. https://doi.org/

[44] 10.1016/j.compeleceng.2019.06.016 
[45] Veselitsky O., Khabarov D. (2019). Trends in the development of distance education in Russia and abroad. Colloquium-journal. No. 3-3 (27). Retrieved from: https://cyberleninka. $\underline{\mathrm{ru} / \text { article/n/tendentsii-razvitiya-distantsionnogo-obrazovaniya-v-rossii-i-za-rubezhom }}$

[46] Vougas, K., Sakelaropoulos, T., Kotsinas, A., Foukas, G. R. P., Ntargaras, A., Koinis, F., \& Georgoulias, V. (2019). Machine learning and data mining frameworks for predicting drug response in cancer: An overview and a novel in silico screening process based on association rule mining. Pharmacol. Ther. 107-109. https://doi.org/10.1016/j.pharmthera.2019.107395

[47] Wahab, N., Hasbullah, N., Zainudin, N., Razali, N. A. M., Yahaya, Y., Alsagoff, S. N., \& Kasran, N. A. (2019). An approach to mixed reality and massive open online courses (MOOC) in learning the military decision making environment. International Journal of Recent Technology and Engineering, 7(5), 548-551

[48] Wikström, C., \& Eklöf, H. (2019). Educational assessment in digital environments: Insights from different assessment contexts. Education Inquiry, 10(1), 1-3. https://doi.org/10.1080/ 20004508.2019.1568779

[49] Xie, H., Zou, D., Zhang, R., Wang, M., \& Kwan, R. (2019). Personalized word learning for university students: a profile-based method for e-learning systems. Comp. in. High. Educ., 31 (2), 273-289. https://doi.org/10.1007/s12528-019-09215-0

[50] Xu, D., Huang, W. W., Wang, H., \& Heales, J. (2014). Enhancing e-learning effec-tiveness using an intelligent agent-supported personalized virtual learning en-vironment: An empirical investigation. Int. J. Inf. Manag. Sci., 51(4), 430-440. https://doi.org/10.1016/j.

[51] im.2014.02.009

[52] Zabaznova, T. A., Patsyuk, E. V., Shchukina, N. V., Karpushova, S. E., \& Surkova, O. A. (2020). The algorithm of creation of territories of rapid socio-economic development in the digital economy. https://doi.org/10.1007/978-3-030-32015-7 9

\section{Authors}

Elvir Munirovich Akhmetshin is with Kazan Federal University, Elabuga Institute of KFU, Russia. ORCID: https://orcid.org/0000-0002-2576-503X.

Vladimir Lvovich Vasilev is with Kazan Federal University, Elabuga Institute of KFU, Russia. ORCID: https://orcid.org/0000-0003-2779-8342 (Email: vlvasilev80 (a)mail.ru).

Artemiy Vladimirovich Kozachek is with Tambov State Technical University, Russia. ORCID: https://orcid.org/0000-0003-0296-093X (Email: avkozachek@list.ru).

Galina Vladimirovna Meshkova is with Bauman Moscow State Technical University, Russia. ORCID: https://orcid.org/0000-0002-3795-0830 (Email: gvmeshkova@inbox.ru).

Tatyana Nikolaevna Alexandrova is with Saint-Petersburg State University of Industrial Technologies and Design, St. Petersburg, Russia. ORCID: https://orcid. org/0000-0002-3069-0001 (Email:tatyana.n.aleksandrova@mail.ru).

Article submitted 2021-05-24. Resubmitted 2021-08-09. Final acceptance 2021-08-10. Final version published as submitted by the authors. 